Available online at GSC Online Press Directory

GSC Biological and Pharmaceutical Sciences

e-ISSN: 2581-3250, CODEN (USA): GBPSC2

Journal homepage: https://www.gsconlinepress.com/journals/gscbps

(REVIEW ARTICLE)

\title{
Immunomodulatory and phytomedicinal properties of watermelon juice and pulp (Citrullus lanatus Linn): A review
}

\author{
Aderiye BI ${ }^{1,}{ }^{*}$, David OM ${ }^{1}$, Fagbohun ED ${ }^{1}$, Faleye $\mathrm{J}^{2}$ and Olajide OM ${ }^{1}$ \\ ${ }^{1}$ Department of Microbiology Ekiti State University, Ado-Ekiti. Nigeria \\ ${ }^{2}$ Department of Chemistry, Ekiti State University, Ado-Ekiti. Nigeria.
}

Publication history: Received on 30 March 2020; revised on 09 April 2020; accepted on 15 April 2020

Article DOI: https://doi.org/10.30574/gscbps.2020.11.2.0079

\begin{abstract}
Watermelon (Citrullus lanatus Linn) is a popular staple summer fruit in the world which is consumed frequently as a dessert, fruit salad and used in garnishing drinks. It is a natural source of antioxidants. Watermelon is an unusual fruit source of the carotenoid lycopene and a rich source of phenolic antioxidants. It contains cucurbitacin E, a triterpene anti-inflammatory phytonutrient and unusual amounts of amino acids like L-arginine and citrulline. Watermelon is an excellent source of immune-supportive vitamin $\mathrm{C}$ and vitamin $\mathrm{A}$. In addition, watermelon is a good source of potassium and magnesium. The nutritional profile of water melon is a full array of nutrients, including carbohydrates, sugar, soluble and insoluble fiber, vitamins, minerals e.g. magnesium and potassium, fatty acids and amino acids. The chemical components of watermelon enhance its capacity to scavenge the low-density lipoprotein (LDL) and high-density lipoprotein (HDL) in a cell membrane. A plethora of evidence shows that it can be effective for weight loss. Several epidemiological studies showed it has phytochemicals that can reduce risk of Cardio Vascular Disease (CVD). Watermelon pomace is reported to be a concentrated source of lycopene as compared to the juice.
\end{abstract}

Keywords: Watermelon; Cucurbitacin; Phytonutrient; Citrulline; Immunity; Vitamins

\section{Introduction}

Watermelon (Citrullus lanatus) is a member of the Cucurbitaceae family native to tropical areas of Africa near Kalahari Desert [1]. Botanists refer to it as a "pepo" which is a fruit having a thick rind and fleshy center [2]. It is largely consumed as refreshing summer fruit, much appreciated because of its refreshing capability, attractive colour, delicate taste and high water content to quench the summer thirst. Watermelon fruits yield about $55.3 \%$ juice, $31.5 \%$ rind and $10.4 \%$ pomace [3]. Carotenoids such as lycopene and $\beta$-carotene are responsible for the red and orange colors of the watermelon respectively. The sweetness of watermelon is mainly due to a combination of sucrose, glucose, and fructose. Sucrose and glucose account for 20-40 \% and fructose for 30-50\% of total sugars in a ripe watermelon [4].

The chemical component of watermelon enhances its capacity to scavenge the low-density lipoprotein (LDL) and highdensity lipoprotein (HDL) in a cell membrane [5]. It has been reported that it can be used to effectively manage weight loss. Several epidemiological reports have shown its loss due to its potency in the management of Cardio Vascular Disease (CVD). As a result, consumption of watermelon has been associated with various health benefits such as lowering the risk of developing heart diseases, age-related degenerative pathologies, and some kinds of cancer [6]. In addition, watermelon is also a rich source of citrulline, which is a nonessential amino acid [7].

\footnotetext{
* Corresponding author: Aderiye BI (jadesolaaderiye@gmail.com)
} 


\section{Watermelon Nutrition and Health Benefits}

Consumption of raw watermelon fruit on hot summer days is a common practice which has been observed across the world. However, to increase utilization and availability throughout the year, watermelon is processed into variety of commercial products [8,9]. The lycopene-rich nature and health benefits of the watermelon juice make it an excellent choice for preparing additional functional foods in order to increase utilization. It has been used in the production of a variety of products like juice, smoothies, jams, sweets, and sauces [10,11].

Watermelon is a good source of minerals and vitamins since it contains 11 minerals and 19 vitamins [12]. It has vitamins such as thiamine $(0.021 \mathrm{mg})$, riboflavin $(0.178 \mathrm{mg})$, niacin $(0.221 \mathrm{mg})$, and folate $(0.045 \mathrm{mg})$. In addition, it has minerals such as potassium (112 mg), magnesium (10.3 mg), calcium (10 mg), phosphorus (11 mg), and iron (0.038 mg) per one gram of watermelon. All these minerals play important roles in cell regulation, maintenance of cell structure and cell differentiation process by acting as co-factors for many enzymes in the cell [13]. The absence of vitamins (e.g ascorbate) may lead to death of the cell. Owing to its reported nutrients, watermelon is regarded as a medicinal plant [14].

Consumption of watermelon is desirable because of its many positive biological effects, which are mostly connected to being fat-free, cholesterol-free, low in sodium, rich in minerals and phytochemicals [15]. As a result, consumption of watermelon provides long-term health benefits such as reduced risk of heart disease, improved blood pressure in hypertension patients, decrease LDL oxidation and exerts a cardio protective effect [16]. Compared to well-known fruits like tomatoes, strawberries, and guavas, watermelon has higher antioxidant capacity $(84.05+3.16-51.10 \mu \mathrm{mol}$ TE/100 g) [6].

Carbohydrates, vitamin and fiber are the major components that make up watermelon. All these components are present in their most beneficial forms. Watermelon has recently received attention for its fewer quantities of fats; it is therefore considered a constituent of a healthy diet low in cholesterol and sodium. Due to its reported nutrients, watermelon is regarded as a medicinal plant [10]. The watermelon fruit has low energy (127 KJ) value and therefore recommended for weight management [17]. Watermelon consumption can be useful in maintaining acid-base balance in the body that has a major role in normal physiology, maintaining appetite and normal digestion [18].

In addition, Adedeji and Oluwalana [19] reported that minerals such as calcium and potassium play an important role in cell regulation, maintenance of the cell structure and cell differentiation process. The U.S. Department of Health and Human Services and U.S. Department of Agriculture The World Health Organization [20], recommended that the optimal diet for everyone is through the consumption of a low-fat, fiber-rich carbohydrates. Watermelon juice and pulp contain considerable amounts of carbohydrates and fiber, which plays a significant role in blood cholesterol and helps in the prevention of large bowel diseases while carbohydrates are the source of energy for the cells.

\section{Immunity and Immune System}

Immunity is the state of being able to resist a particular infection or toxin. The term "immunity" is defined as body's natural defense system against a vast group of diseases and illnesses. The factors which trigger immunity include previous infection, immunization and various external stimuli [21]. Based on the function, immune system has been categorized in two broad sections, innate immune system and adaptive immune system. The innate response is usually triggered when microbes are identified by "Pattern Recognition Receptor" (PRR), which recognizes components that are conserved among broad groups of microorganisms while the adaptive immune system is antigen-specific and requires the recognition of specific antigens [22].

Immunomodulators refer to those substances capable of inducing, amplifying and inhibiting any component or phase of the immune system. Immunostimulators and immunosuppressants are two types of immunomodulators known [23]. The function and efficiency of the immune system are influenced by various exogenous and endogenous factors resulting in either immunosuppression or immunostimulation to control auto-immune disorders when excessive tissue damage occurs. Several agents possessing an activity to normalize or modulate pathophysiological processes are called immunomodulators [24].

The immunomodulatory characteristics of plant-based therapeutics have gathered attention of researchers. Innovative technologies and the excessive research on immunomodulatory natural products, plants, their extracts and their active moieties with immunomodulatory potential, may provide us with valuable entities to develop as novel immunomodulatory agents to supplement the present chemotherapies [25]. An example of immunomodulatory drugs is thialidomide and lenalidomide which are used in the treatment of auto immune disease like multiple sclerosis. 


\subsection{Immunological Properties of Plants}

Plants have been identified as the most important source for the curability of various diseases in the form of medicines [26]. Plants are the main source of drugs used from the ancient times as herbal remedies for health care, prevention and cure of various diseases and ailments. Plants secondary metabolites such as terpenes, phenolics and nitrogen containing compounds have been implicated for most plants therapeutic activities [27]. The prevention and treatment of diseases using plant-based medicines have been reported in human history. In all cultures and through all ages different parts (such as bark, root and leaves) of a huge number of plants have been used as drugs against all kinds of ailments. For example, Vinblastine, vincristine and their semi-synthetic derivatives isolated from the Madagascar periwinkle (Catharanthus roseus) have been used as chemotherapy medication to treat a number of types of cancer, which include acute lymphocytic leukemia, acute myeloid leukemia and small cell lung cancer [28]. Capsaicin from chili peppers (Capsicum species), is a neuropeptide releasing agent selective for primary sensory peripheral neurons. Used typically, capsaicin aids in controlling peripheral nerve pain [29].

Paclitaxel from Pacific yew (Taxus brevifolia) is a chemotherapy medication used to treat a number of cancers, lung cancer, kaposi sarcoma, cervical cancer and galantamine from the Caucasian snowdrop (Galanthus caucasicus) are examples of medicines based on plant compounds [30]. The plant-based compounds that served as lead structures and/or were chemically altered are dicoumarol (0.1\%) which is found in spoiled sweet clover (Melilotus officinalis), artemisinin (0.02\%) derived from wormwood (Artemisia annua), camptothecin (2.46\%) derived from Camptothec (Camptotheca acuminata), morphine $(0.5 \%)$ derived from opium poppy (Papaver somniferum) and salicylic acid (0.03 $\%$ ) derived from willow tree (Salix alba) [31]. Recently the clinical potential of six plant-derived anti-inflammatory compounds: curcumin, colchicine, resveratrol, capsaicin, epigallocatechin-3-gallate (EGCG), and quercetinin have been highlighted by Fürst and Zündorf [32].

\subsection{Immunological Properties of Watermelon}

Watermelon (Citrullus lanatus) is a popular staple summer fruit in the world which is consumed frequently as a dessert, fruit salad and in garnishing drinks. It is a natural source of antioxidants [33]. Watermelon (Citrullus lanatus) is an unusual fruit source of the carotenoid lycopene and a rich source of phenolic antioxidants and contains cucurbitacin E; a triterpene anti-inflammatory phytonutrient. Watermelon contains unusual amounts of the amino acids and citrulline [34]. Watermelon is also an excellent source of immune-supportive vitamin C and vitamin A (9.0 mg), potassium (11.2 $\mathrm{mg}$ ) and magnesium (10.2 mg).

The nutritional profile of watermelon is full array of nutrients, including carbohydrates (127 g), sugar (6.2 g), soluble and insoluble fiber $(0.4 \mathrm{~g})$, and sodium (1 mg) among others [19]. The consumption of watermelon fruit juices could have both positive and negative effects on consumers. As a result, consumption of watermelon provides long-term health benefits such as reduced risk of heart disease, improved blood pressure in hypertension patients and decrease low-density lipoprotein (LDL) oxidation [10].

However, watermelon is an excellent source of water and an equally great source of dietary fibre. Hence, consuming contaminated juice of the fruit may give rise to infection of digestive systems like diarrhoea [17]. The fruit supplies an excellent medium for the growth of both pathogenic and spoilage microorganisms. Watermelon fruit juices processed under hygienic conditions could play important role in enhancing consumer's health through inhibition of breast cancer, congestive heart failure (CHF) and urinary tract infection [35].

Freshly extracted watermelon juices may not always be safe owing to the heavy load of microbes [36]. Major ingredients of juices such as water, sugar and natural fruit pulp may also carry some microbial contaminants which may cause spoilage of the drinks or gastrointestinal disorders to consumers [37]. Development of new products where two or more kinds of fruit juices are blended to obtain a product that combines the nutritional value of both fruits with the benefit of a pleasant taste has been encouraged by the food industry and has been well accepted by consumers [38].

\subsection{Anti-oxidant Properties of Watermelon}

The therapeutic effects of $C$. lanatus fruit have been reported and attributed to certain phytochemical compounds [39]. For instance, beta carotene and lycopene have been established to play a key role in the treatment of cancer and cardiovascular diseases [40]. The therapeutic effect of watermelon has been ascribed to its ability to scavenge free radicals [41,42]. Lycopene is an acyclic isomer of $\beta$-carotene. It is has been demonstrated to play a prominent role in the treatment and management of ailments such as cancer and cardiovascular diseases [42], also reported as having analgesic and anti-inflammatory effects [43,44], with anti-ulcerative activity [45,46], antimicrobial activity [47], laxative activity of the fruit and hepatoprotective [43]. 
In vitro antioxidant studies have been conducted to screen various plant containing phenolic and flavanoids constituents $[2,48]$. Plant derived antioxidant compounds, flavonoids and phenolics have received considerable attention because of their physiological effect like antioxidant, anti-inflammatory, antitumor activities and low toxicity compared to those of synthetic phenolic antioxidants such as butylated hydroxyanisole, butylated hydroxytoluene and propyl gallate [49,50].

\section{Watermelon Phytochemicals and their benefits to Human Health}

Fresh fruits and vegetable juices are important parts of modern day diet in many parts of the world as they are rich sources of nutrients such as vitamins, minerals and other naturally occurring phytochemicals which are of health and therapeutic benefits [51]. Fruit and vegetable intake has been found to reduce the incidence of some chronic diseases such as atherosclerosis and cancers $[52,53]$. The reason for this relationship appear to be multi-faceted and include compounds in plants that are used as electron scavengers (such as lycopene and $\beta$-carotene), detoxification agents (such as halothane and isoflurane), or as plant defense response compounds (e.g., terpenoids, phenolics and alkaloids).

Consumption of food rich in phytochemicals (such as phenolics found in citrus fruits and lycopene found in tomato products and watermelon) has long-term benefits to human health [54]. Phytochemicals such as lycopene and $\beta$ carotene have been shown to have antioxidant, anti-inflammatory and hypotensive properties; therefore, their inclusion on diet results in positive effects on the human body. They prevent oxidative changes in the plasma lipoprotein structure by preventing the formation of enzymes involved in cholesterol synthesis [54], prevent macular degeneration and the development of cataracts through anti-inflammatory mechanisms [55] and reduce the nitrogen oxide bioavailability by scavenging the oxidation reaction and they synthesize prostacyclin which causes blood vessels to relax and become reduced. Within the enterocytes, uncleaved carotenoids and retinyl esters (derived from retinol) are incorporated into triglyceride-rich lipoproteins called chylomicrons secreted into lymphatic vessels, and then released in the bloodstream [56]. They may also enhance the immune system function and inhibit tumor progression in some cancers [57].

\subsection{Lycopene}

Lycopene, a red pigment of the carotenoid class found in only a few fruits and vegetables, is a powerful oxygen radical scavenger and highly effective antioxidant [58]. A high dietary intake of tomatoes, rich in lycopene content, is associated with a lower risk of certain cancers, primarily of the prostate [59]. Watermelon and tomatoes are the most familiar sources of lycopene containing on average 48.6 and $30.1 \mu \mathrm{g}$ lycopene/g fresh weights respectively [60,61]. It is visible as a red pigment that gives fruits such as watermelon, guava, red bell peppers and tomato their desirable colour and contributes to about $21-43 \%$ of the total carotenoids, accumulated in the human tissue $[7,48,54]$. Therefore, it is incorporated into the body through diet. The estimated recommended lycopene intake in developed countries is 5-7 $\mathrm{mg}$ /day and it is assumed that approximately 10-30\% lycopene is absorbed in the human body [62]. After consumption, lycopene enters the stomach for digestion; it changes into a lipid phase, which is dispersed under the influence of bile salts and pancreatic lipases $[63,70]$.

Lycopene is a strong antioxidant; therefore, it is an effective free radical scavenger and oxygen quencher among all carotenoids [64]. Lycopene-scavenging rate is higher than $\beta$-carotene and tocopherol $[1,65]$. Watermelon contains the highest bioavailable lycopene which is about $60 \%$ more than that found in tomato making it the lycopene leader among fresh produce [66].

Lycopene is a type of carotenoid that serves as antioxidant. Lycopene imparts red colour in watermelon though its contents varies in watermelon however, the amounts are generally greater than that of tomato. Lycopene lowers the risk of some types of cancer. It helps to reduce cancer risk by lowering insulin-like growth factor. It also helps to lower cholesterol and blood pressure [67]. Lycopene has been classified as useful in the human diet for prevention of cardiovascular diseases as well as certain types of cancer and may protect the skin from ultraviolet light damages [68]. The red-fleshed watermelon varieties contain high lycopene $(3.38-11.34 \mathrm{mg} / 100 \mathrm{~g}$ ) and varying amount of $\beta$-carotene (3.38-11.34 mg/100g). The quantity of lycopene varies depending upon the variety and growing conditions [69]. Lycopene has potential to prevent various ailments like dyslipidemia, diabetes, neurodegenerative diseases, osteoporosis among others [6,66].

Thermal processing induces isomerization of lycopene bioavailability [70]. Lycopene has become a compound of interest to both food and health researchers due to its reported benefits on human health. Lycopene has a higher ratio of 1:12 to carotene in watermelon and this yields remarkable antioxidant capacity. It bears significant potential for consideration in both the treatment and the prevention of some chronic diseases such as heart disease. According to this specific characteristic, foods high in lycopene are referred to as functional foods [71]. 
Recently, the demand for natural form of lycopene has increased, mainly because it is effective at curbing the destructive free radicals including nitrogen dioxide, sulfide, singlet oxygen and inhibiting DNA and cellular membrane damage [72]. Because of its antioxidant functions, it reduces lipids by preventing the formation of enzymes involved in cholesterol synthesis [71]. The consumption of fruits that are rich in lycopene such as watermelon is therefore considered pivotal due to the role it plays in prevention of chronic diseases; it is nontoxic without known side effects.

\subsection{B-Carotene}

Beta ( $\beta$-) carotene is a lipophilic macronutrient and an insoluble vitamin which includes a group of unsaturated nutritional organic compounds including retinoic, retinal and retinol [73]. It is made of 40 carbon atoms and contains 11 conjugated and 2 unconjugated double bonds [63]. Beta ( $\beta$-)carotene has a very low solubility in a number of solvents such as water and ethanol due to its highly conjugated long chain [74]. Visible as the orange color in fruits and vegetables, it serves as a precursor for vitamin A in a human body [75]. Beta-carotene cannot be synthesized by the body; therefore, it is primarily derived from plant-based foods such as watermelon, carrots, sweet potatoes, spinach, and mangoes [76].

Watermelon contains substantial quantities of $\beta$-carotene $(461 \mu \mathrm{g})$ found in a cup of diced watermelon [75]. It has the ability to exhibit both antioxidant activity and pro-oxidant properties [77]. Because of these properties, $\beta$-carotene has desirable power in inactivating certain Reactive Oxygen Species (ROS) and it exerts neuroprotective effect against LDL and HDL [4]. The antioxidant potential of $\beta$-carotene has been widely investigated and some positive results have been reported [78]. Among other important effects on human health, $\beta$-carotene intensifies platelet aggregation increasing the growth factor expression, which leads to the reconstruction of blood vessel walls [63]. Among other functions, it has been shown to be important for the maintenance of the immune system; it supports cell growth and differentiation playing a role in the formation and maintenance of the heart, kidney and other organs [79].

Beta $(\beta$-) carotene- enriched diet neutralizes the damaging molecules which results in defying age naturally [48, 80]. It helps the body to absorb light in the eyes for good vision and further functions as growth factor for epithelial cells and modulates gene function mainly due to the enzyme di-oxygenase, which is present in the human small intestine mucosa and it converts $\beta$-carotene into retinol [63]. Beta ( $\beta$-) carotene is also known for its potential anticancer attributes [81]. This is because it may interact with other phytochemicals in fruits and vegetables and have a greater effect on the body than do supplements. It plays an important role in reducing the risk type 2-diabetes and lowering metabolic syndrome in middle-aged adults [82]. Children, pregnant and lactating women are reported to be the most vulnerable groups to vitamin A deficiency [83]. Due to the health benefits of this phytochemical, the demand for it as an additive in functional food applications as well as a supplement is growing.

\subsection{Vitamins}

The amount of Vitamin A in watermelon ranged between 569 and 864.88 IU. This vitamin has been reported to enhance optimal functioning of the eyes. The deficiency in vitamin A has been reported to produce highest effects in children, pregnant and lactating women [84]. Watermelon is rich in vitamin B (13.53 mg/100g) and responsible for the production of energy in the body. Taking into consideration these health-promoting parameters, watermelon extracts such as Vitamin C, Amino acids and lycopenes are powerful antioxidants which can be incorporated into cosmetics, food, and pharmaceutical products $[85,86]$.

The presence of vitamin C (ascorbic acid) has been reported to be higher in the rind of watermelon compared to its pulp. Ascorbic acid is water-soluble and have being reported to take an active roles in many biological processes. Apart from its antioxidant property, ascorbic acid has high scavenging ability for free radicals generated in the cells during catabolic activities and oxidative stress. The antioxidant properties of the fruit makes it to serve medicinal purpose apart from its nutritional quality $[87,88]$. Vitamin $C$ also reduces serum alanine amino-transferase and the risk of inadequacy or adverse health effects. It protects the body against diseases like scurvy and simple cold [84].

Vitamin C is used as a general description for all organic compounds exhibiting biological activity of ascorbic acid [89]. It has two main components which are ascorbate and dehydroascorbic acid [90]. Vitamin C is a water-soluble essential nutrient that is frequently added to a variety of food products for nutrient enhancement and supplementation important for biosynthesis of collagen and certain hormones [91].

Watermelon has been identified a good source of vitamin C [10], with the fresh juice containing about $3.72 \mathrm{mg} / 100 \mathrm{~mL}$ [66]. As with other parameters, the vitamin C content varies due to difference in the watermelon cultivars and 
environmental factors. For example, a cup of watermelon juice contains $20 \%$ of the daily value for vitamin C. Ten (10 $\mathrm{mg}$ ) milligram dosage daily of vitamin $\mathrm{C}$ will prevent nutritive deficiency and scurvy. However, 90-500 mg daily is recommended for optimal benefits [84].

Vitamin C may improve the quality of life for cancer patients in several potential mechanisms. Patients with cancer usually suffer from vitamin C deficiency and are exposed to very high oxidative stress [92]. Therefore, oral intake of this vitamin through natural sources may relief fatigue and various other symptoms caused by a state of chronic vitamin $\mathrm{C}$ deficiency in these patients [22].

The other mechanism is that vitamin $\mathrm{C}$ has anticancer properties, therefore, consumption of foods that contain this vitamin $\mathrm{C}$ may suppress cancer cell in patients by generating pro-oxidant activity, depending on blood concentrations $[3,93]$. It has long been reported beneficial in the prevention and treatment of a variety of ailments, scurvy, simple cold as well as being stress resistant [94]. A proper intake of vitamin C-enriched diet over a lifetime will help to maintain our current health and prevent future ailments $[1,95]$. As with other phytochemicals, consumption of natural vitamin $C$ is recommended as opposed to synthetic ones in the form of supplements.

\subsection{Cucurbitacins}

Watermelon (Citrullus spp.) is one of the most popular sweet fruits and accounts for $7 \%$ of the area worldwide devoted to fruit and vegetable production. Watermelon possesses a wide range of medicinal potentials. Due to the bioactive compounds, cucurbitacins found in watermelon fruits can play an important role in the improvement of disorders like indigestion, dysentery, gastroenteritis, cold, toothaches and diabetes as well as in wound healing, as reported in Pakistan, India, China, other parts of Asia and Africa [96].

Cucurbitacins are a group of tetracyclic triterpenes with a cucurbitane skeleton that were initially identified in the Cucurbitaceae family [97]. There are more than 10 classes of cucurbitacins and their derivatives [98]. The cucurbitacins are abundant in Cucurbitaceae family members and have been found useful as inhibitors of cancer cells, inhibit actin polymerization, capillary permeability and also serve as anti-inflammatory [99]. Cucurbitacins are generally bitter in taste and at low concentrations in watermelon species its sweet taste also exhibits very low bitter flavors. Cucurbitacin diversity or the presence of their derivatives in different Citrullus species has been responsible for their phytomedicinal applications.

\subsection{Citrulline}

Citrulline is a non-protein amino acid that is reported to be abundant in watermelon [89]. Citrulline is considered a potent osmolyte and radical scavenger against drought/salt stress [72]. Citrulline is found in a watermelon, varying in amounts from 0.7 to $3.6 \mathrm{mg} / \mathrm{g}$ fresh fruit. A recent study done on 56 cultivars found the mean value of citrulline as 3.1 $\mathrm{mg} / \mathrm{g}$ that shows no correlation with cultivar type. Research is still ongoing to determine which part of the watermelon contains more citrulline than the other $[99,100]$. L-citrulline has been reported to conjugate with as many other NOboosting supplements nitric oxides in a better way than L-arginine. Reduction in/or lack of nitric acid production could lead to the development of essential hypertension, heart failure reduction of skeletal muscle metabolism that may progress to development of insulin resistance and type 2 diabetes and other age-related muscle wasting [101]. Lcitrulline may have a positive impact on endothelial vasodilatory function because it is efficiently converted to Larginine and consequently transformed to nitric oxide [102].

The amino acid, citrulline has been studied by medical researchers for their usefulness in sickle cell anaemia, immune function, wound healing and cardiovascular health [103]. Citrulline, a non-essential amino acid, is a precursor of arginine, a semi-essential amino acid needed by infants and seriously ill or injured adults [104]. Watermelon is a unique source of amino acids [105]. Citrulline is produced naturally in the body by an enzymatic reaction of nitrogen-carbon contained l-glutamine and mainly absorbed in the intestine [106].

Plasma nitric oxide is rapidly metabolized to nitrite and nitrate, which have as been considered as precursors for nitric oxide synthesis in the cell [107]. L-citrulline and watermelon supplements on vascular and metabolic physiology and their potential therapeutic impact on cardiometabolic health have been reported. L-citrulline also has direct and indirect effects on skeletal muscle and adipose tissue metabolism, which are key mediators for the development of cardiometabolic disorders. The health-related applications of L-citrulline supplementation are largely predicated on the capacity for L-citrulline to increase L-arginine availability for nitric oxide production [43]. As an efficient hydroxyl radical scavenger and strong antioxidant, a diet rich in citrulline is associated with several health benefits [7]. Citrulline was found to be efficient in sections such as skeletal, pharmacology, immunology and neurology. It is important for 
young adults with trauma, burn injury, massive small bowel resection, and renal failure [93]. It has also been found to be important in the prevention of anaemia [95].

\section{Total Polyphonic Content}

Polyphenols, commonly known as polyphenolic compounds, are defined as structural class organic chemicals characterized by the presence of large multiples of phenol structural units including phenolic acids, flavonoids, stilbenes, and lignans [108,109]. Scientific evidence has suggested that due to their antioxidant properties, daily consumption of foods and beverages rich in polyphenols induces positive effects on human health, which results in having specific biological activities affecting gene expression, cell signaling and adhesion [110]. They are the most dominant antioxidants in a diet derived from fruits and vegetables. They have the ability to stop the formation of ROS (Reactive Oxygen Species) in a human body.

However, the health effects of polyphenols depend on both their respective intakes and their bioavailability [110]. Thus, consumption of watermelon juice can serve as a medicinal alternative [6]. Polyphenols have evoked considerable interest among nutritionists, food manufacturers, and consumers because of their safety and potential therapeutic value due to the natural compounds such as lycopene and $\beta$ - carotene which are also present in watermelon [48].

\section{Future Perspectives}

Even though watermelon (Citrullus lanatus) was found to be the highest source of lycopene and citrulline among all fruits, research has found that at least $85 \%$ of our dietary lycopene is supplied by tomato and tomato based products; therefore, there is a need to produce more watermelon-based products. Since watermelon shows compatibility with other fruits, it can be used together with those fruits to manufacture products that are more commercial. Research has indicated that the lycopene content of watermelon is not totally depleted by processing methods [111]. Therefore, lycopene can be extracted from the watermelon to be used in pharmaceuticals and food manufacturing industries as an ingredient. Monitoring quality attributes of watermelons during processing is still an ongoing research in order to produce high-quality products [112]. Moving forward into the future, it is important to determine the internal qualities of watermelon as affected by maturity and processing in order to provide intensive understanding to food processors..

\section{Conclusion}

The production of juice from watermelon (Citrullus lanatus) is important in that it will reduce wastage of the fruits by farmers and provide vitamins, minerals and the anti-oxidant compound (lycopene) to their respective consumers. It also reduces loss to economy of the country. This study has proved that watermelon juice contains some beneficial nutrients and therefore, its production should be encouraged.

\section{Compliance with ethical standards}

\section{Acknowledgments}

This study was financially supported by the Tertiary Education Trust Fund Grant (with grant number AD/ORD/44/TET/VOL.3/127).

\section{Disclosure of conflict of interest}

The authors declare that they have no conflicts of interest.

\section{References}

[1] Naz A, Butt MS, Sultan MT, Qayyum MMN and Niaz RS. (2014). Watermelon Lycopene and Allied Health Claims. Exclixer Journal, 13, 650-666.

[2] Mehra M, Pasricha V and Gupta RK. (2015). Estimation of nutritional, phytochemical and antioxidant activity of seeds of muskmelon (Cucumis melo) and watermelon (Citrullus lanatus) and nutritional analysis of their respective oils. Journal of Pharmacognosy and Phytochemistry, 3, 98-102. 
[3] Romdhane MB, Haddar A, Ghazala I, Jeddou KB, Helbert CB and Ellouz-Chaabouni S. (2017). Optimization of polysaccharides extraction from watermelon rinds: structure, functional and biological activities. Food Chemistry, 216, 355-364.

[4] Lum T, Connolly M, Marx A, Beidler J, Hooshmand S, Kern M, Liu C and Hong MY. (2019). Effects of fresh watermelon consumption on the acute satiety response and cardiometabolic risk factors in overweight and obese adults. Nutrients, 11(595), 1-13.

[5] Friedewald WT, Levy RI and Fredrickson DS. (1972). Estimation of the concentration of low-density lipoprotein cholesterol in plasma, without use of the preparative ultracentrifuge. Clinical Chemistry. 18, 499-502.

[6] Choudhary BR, Haldhar SM, Maheshwari SK, Bhargava R and Sharma SK. (2015). Phytochemicals and antioxidants in watermelon (Citrullus lanatus) genotypes under hot arid region. 85. Indian Journal of Agricultural Sciences, 85(3), 414-417.

[7] Soteriou GA, Kyriacou MC and Gerasopoulos ASD. (2014). Evolution of watermelon fruit physicochemical and phytochemical composition during ripening as affected by grafting. Journal of food chemistry, 165, 282-289

[8] Ijah UJJ, Ayodele HS and Aransiola SA. (2015). Microbiological and some sensory attributes of watermelon juice and watermelon-orange juice mix. Journal of Food Resource Science, 4, 49-61.

[9] Asoso OS, Ogunmefun OT, Adelegan O and Farida S. (2019). Chemical composition, nutritional values and antibacterial activities of watermelon seed (Citrullus lanatus). International Journal of Biochemistry Research and Review, 27(1), 1-9.

[10] Jumde AD and Shukla RN. (2014). Gousoddin. Development and Chemical Analysis of Watermelon Blends with Beetroot Juice during Storage. International Journal of Science Engineering Technology, 4, 2395-4752.

[11] Abdu-Zubairu SB, Gimba WJ, Mamza BK and Highina Y. (2018). Proximate analysis of dry watermelon (Citrullus lanatus) rind and seed powder. Journal of Scientific and Engineering Research, 5(3), 473-478.

[12] Martirosyan DM. (2015). Vitamin C: Optimal dosages, supplementation and use in disease prevention. Journal of Clinical Nutrition, 5, 89-107.

[13] Campbell I. (2017). Macronutrients, Minerals, Vitamins and Energy. Physiology, 3, 141-146.

[14] Said MA. (2014). A study in the variability of some nutrient contents of watermelon (Citrullus Lanatus) before and after ripening consumed within Kano Metropolis, Nigeria. International Journal of Science Research, 3, 13651368.

[15] Shukla RN and Jumde AD. (2015). Development and Chemical Analysis of Watermelon Blends with Beetroot Juice during Storage. International Journal of Science and Engineering Technology, 4, 2395-4752.

[16] Figueroa A, Wong A and Kalfon R. (2013). Effects ofWatermelon Supplementation on Aortic Hemodynamic Responses to the Cold Pressor Test in Obese Hypertensive Adults. American Journal of Hypertens, 27, 899-906.

[17] Gry J, Søborg I and Andersson HC. (2016). Cucurbitacins in Plant Food. Nordic Council of Ministers, Copenhagen.

[18] Maheshwari SK, Choudhary BR, Haldhar SM, Bhargava R and Sharma SK. (2015). Phytochemicals and Antioxidants in Watermelon (Citrullus lanatus) Genotypes under Hot Arid Region. Indian Journal of Agricultural Science, 85, 414-417.

[19] Adedeji TO and Oluwalana IB. (2013). Physico-chemical, sensory and microbial analysis of wine produced from watermelon (Citrullus lanatus) and Pawpaw (Carica papaya) Blend. Food Science Quality Management, 19, 4150 .

[20] US Department of Health and Human Services and U.S. Department of Agriculture. 2015-2020 Dietary Guidelines for Americans, 8th ed, 2015.

[21] Baxter D. (2007). Active and passive immunity, vaccine types, excipients and licensing. Occupational Medicine, $57,552-556$.

[22] Vesely MD, Kershaw MH, Schreiber RD and Smyth MJ. (2011). Natural innate and adaptive immunity to cancer. Annual Review Immunology, 29, 235-271.

[23] Ramalingum QA and Tandon JK. (2014). Immunomodulators: International Journal of Immunology, 84, 32-47.

[24] Puri A, Saxena R, Saxena RP, Saxena KC, Srivastava V and Tandon JS. (1994). Immunostimulant activity of Nyctanthes arbortristis L. Journal of Ethnopharmacology, 42, 31-37. 
[25] Kalia AN. (2005). Text Book of Industrial Pharmacognosym. Oscar Publication, New Delhi, India. International Journal of Pharmacognosy, 33, 297-304.

[26] Guerra 0, Pomari F and Moratti M. (2003). Plants as the main source of drugs. Medical Research Review, 22, 5583.

[27] Timothy O, Idu M, Falodun A and Oronsaye FE. (2008). Preliminary phytochemistry and antimicrobial screening of methanol extract of Baissea axillaris Hau. leaf. Journal of Biological Science, 8, 239-241.

[28] Wang X. (2009). Plant based drug. International Journal of Pharmacotherapy Biological Science, 10, 711-738.

[29] Govindarajan NW. (2012).Capsicum-production technology, chemistry and quality. Journal of Food Science and Nutrition, 29(6), 434-474.

[30] Deng GD. (2015). Pacitaxel: Medicine based on plant compounds. American Societies of Health System Pharmacists Journal, 41, 335-346.

[31] Oberlies NH and Kroll DJ. (2004). Camptothecin and taxol: historic achievements in natural products research. Journal of Natural Products, 67, 129-135.

[32] Fürst R and Zündorf I. (2014). Plant-derived anti-inflammatory compounds: hopes and disappointments regarding the translation of preclinical knowledge into clinical progress. Mediate Inflammatory, 14, 68-32.

[33] Alim-un-Nisa A, Javed S, Firdous MK, Saeed SH and Ejaz N. (2012). Nutritional aspects and acceptability of watermelon juice syrup. Pak. Journal of Food Science, 22, 32-35.

[34] Dimitrovski D, Bicani D, Luterotti SC, Twisk CV, Buijnsters JG and Doka O. (2010). The concentration of translycopene in postharvest watermelon: An evaluation of analytical data obtained by direct methods. Postharvest Biological Technology, 58, 21-28.

[35] Bello 00, Bello TK, Fashola MO and Oluwadun A. (2014). Microbiological quality of some locally-produced fruit juices in Ogun State, South Western Nigeria. E3 Journal of Microbiological Research, 2, 1-8.

[36] Alam MK, Hoque MM, Morshed S, Akter F and Sharmin KN. (2013). Evaluation of watermelon (Citrullus lanatus) juice preserved with chemical preservatives at refrigeration temperature. Journal of Scientific Research, 5, 407414.

[37] Asha S, Nithisha K, Niteesha G, Bharath KR and Ravikumar V. (2014). Evaluation of microbial quality of street vended vegetable and fruit juices. International Research Journal of Biological Science, 3, 60-64.

[38] Ameh BA, Gernah DI, Obioha 0 and Ekuli GK. (2015). Production, quality evaluation and sensory acceptability of mixed fruit juice from pawpaw and lime. Food Nutritional Science, 6, 532-537.

[39] Yadav RNS and Agarwala M. (2011). Phytochemical analysis of some medicinal plants. Journal of Phytology. 3, 10-14.

[40] Charoensiri R, Kongkachuichai R, Suknicom S and Sungpuag P. (2009). Beta-carotene, lycopene and alphatocopherol contents of selected Thai fruits. Food Chemistry, 113, 202-207.

[41] Leong LP and Shui G. (2002). An investigation of antioxidant capacity of fruits in Singaporemarkets. Food Chemistry, 76, 69.

[42] Lewinsohn E, Sitrit Y, Bar E, Azulay Y, Ibdah M, Meir A, Yosef E, Zamir D and Tadnor Y. (2005). Not just colorscarotenoid degradation as a link between pigmentation and aroma on tomatoes and watermelon fruits.Trends. Food Science and Technology, 16, 407-415.

[43] Rimando AM and Perkins-Veazie PM. (2005). Determination of citrulline in watermelon rind. Journal of Chromatograph, 1078, 196-200.

[44] Madhavi P, Rao M, Vakati K, Rahman H and Eswaraiah MC. (2012a). Evaluation of antiinflammatory activity of Citrullus lanatus seed oil by in vivo and in vitro models. International Research Journal Pharmaceutical and Applied Science, 2(4), 104-108.

[45] Alok B, Rajeev K, Vivek D and Niyaz A. (2012). Evaluation of anti-ulcer activity of Citrullus Lanatus seed extract in wistar albino rats. International Journal of Pharmacy and Pharmaceutical Sciences, 4(5), 135-139.

[46] Okunrobo O, Uwaya L, Imafidon JE, Osarumwense K, Omorodion PE and Jude E. (2012). Quantitative determination, metal analysis and antiulcer evaluation of methanol seeds extract of Citrullus lanatus Thunb (Cucurbitaceae) in rats. Asian Pacific Journal of Tropical Disease, 261-265. 
[47] Elsir L and Hassan A. (2011). In vitro antimicrobial activities of chloroformic, hexane and ethanolic extracts of Citrullus lanatus var. citroides. Journal of Medicinal Plants Research, 5(8), 1338-1344.

[48] Castro-López C, Ventura-Sobrevilla JM, González-Hernández MD, Rojas R, Ascacio-Valdés JA, Aguilar CN and Martínez-Ávila GCG. (2017). Impact of extraction techniques on antioxidant capacities and phytochemical composition of polyphenol-rich extracts. Food Chemistry, 237, 1139-1148.

[49] Chidambara KN, Vanitha A, Mahadeva Swamy M and Ravishankar GA. (2003). Antioxidant and antimicrobial activity of Cissus quadrangularis. Latent Journal of Medicinal Food, 6(2), 99-105.

[50] Sharififar F, Dehghan-Nudeh G and Mirtajaldini M. (2009). Major flavonoids with antioxidant activity from Teucrium polium. Food Chemistry, 112, 885-888.

[51] Ukwo SP, Ndaeyo NU and Udoh EJ. (2011). Microbiological quality and safety evaluation of fresh juices and edible ice sold in Uyo Metropolis, South-South, Nigeria. Internet Journal of Food Safety, 13, 374-378.

[52] Steinmetz KA and Potter JD. (1996). Vegetables, fruit, and cancer prevention: a review. Journal of American Dietetic Association, 96 (10), 27-39.

[53] Joshipura KJ, Hu FB and Manson JE. (2001). The effect of fruit and vegetable intake on risk for coronary heart disease. Annual International Medicine, 134, 11-14.

[54] Elumalai M, KArthika B and Usha V. (2013). Lycopene - role in cancer prevention. International Journal of Pharmacotherapy Biological Science, 4, 371-378.

[55] Khao HE, Khan AW and Wuan PS. (2015). A randomized, placebo-controlled, clinical trial of high-dose supplementation with vitamins $\mathrm{C}$ and $\mathrm{E}$, beta carotene, and zinc for age-related macular degeneration and vision loss: AREDS Report No. 8. Archives of Ophthalmolology, 119, 1417-1436.

[56] Wang XD. (2014). Carotenoids. In: Ross CA, Caballero B, Cousins RJ, Tucker KL, Ziegler TR, eds. Modern Nutrition in Health and Disease. $11^{\text {th }}$ Ed: Lippincott Williams \& Wilkins, 427-439.

[57] Sivudu SN, Umamahesh K and Reddy OVS. (2014). A comparative study on probiotication of mixed watermelon and tomato juice by using probiotic strains of lactobacilli. International Journal of Curriculum Microbiological Applied Sciences, 3, 977-984.

[58] Gerster H. (1997). The potential role of lycopene for human health. Journal of American College of Nutrition, 16,109-126.

[59] Giovannucci E. (2002). A review of epidemiologic studies of tomatoes, lycopene, and prostate cancer. Exponental and Biological Medicine (Maywood), 227, 852-859.

[60] Holden JM, Eldridge AL, Beecher GR, Buzzard IM, Bhagwat SA, Davis CS, Douglass LW, Gebhardt, SE, Haytowitz, DB and Schakel S. (1999). Carotenoid Content of U.S. Foods: An Update of the Database. Journal of Food Composition Analysis, 12, 169-196.

[61] Kehili M, Kammlott M, Chouraa S, Zammelc A, Zetzl C, Smirnova I, Allouche N and Sayadi S. (2017). Supercritical $\mathrm{CO}_{2}$ extraction and antioxidant activity of lycopene and $\beta$-carotene-enriched oleoresin from tomato (Lycopersicum esculentum L.) peels by product of a Tunisian industry. Food Bioproducts Processing, 102, 340349.

[62] Petyaev IM. (2016). Lycopene deficiency in ageing and cardiovascular disease. Oxoid Med. Cellular Longevity. 16.

[63] Kulczynski B, Gramza-Michałowska A, Kobus-Cisowska J and Kmiecik D. (2017). The role of carotenoids in the prevention and treatment of cardiovascular disease- current state of knowledge. Journal of Functional Foods, 38, 45-65.

[64] Oberoi DPS and Sogi S. (2017). Utilization of watermelon pulp for lycopene extraction by response surface methodology. Food Chemistry, 232, 1-7.

[65] Duarte PF, Chaves MA, Borges, CD and Mendonca C. (2016). Avocado: Characteristics, health benefits and uses. Cience Rural, 46, 747-754.

[66] Rajabi MS, Moniruzzaman M, Mahmood H, Sivapragasam M and Bustam MA. (2017). Extraction of $\beta$-carotene from organic phase using ammonium based ionic liquids aqueous solution. Journal of Molecular Liquids, 227, 1520 . 
[67] Edwards AJ, Vinyard BT, Wiley ER, Brown ED, Collins JK, Perkins-Veazie P, Baker RA and Clevidence BA. (2003). Consumption of watermelon juice increases plasma concentrations of lycopene and beta-carotene in humans. Journal of Nutrition, 133, 1 043-50.

[68] Perera CO and Yen GM. (2007). Functional properties of carotenoids in human health. International Journal of Food Properties, 10, 201-30.

[69] Fish WW and Davis AR. (2003). The effects of frozen storage conditions on lycopene stability in watermelon tissue. Journal of Agriculture and Food Chemistry, 51, 3582-5.

[70] Oberoi DPS and Sogi S. (2017). Utilization of watermelon pulp for lycopene extraction by response surface methodology. Food Chemistry, 232, 1-7.

[71] Hong MY, Hartig N, Kaufman K, Hooshmand S, Figueroa A and Kern M. (2015). Watermelon consumption improves inflammation and antioxidant capacity in rats fed an atherogenic diet. Nutrition Research, 35, 251-258.

[72] Kyriacou MC, Leskovar DI, Colla G and Rouphael Y. (2018). Watermelon and melon fruit quality: the genotypic and agro-environmental factors implicated. Science of Horticulture, 30, 8-12.

[73] Rajabi MS, Moniruzzaman M, Mahmood H, Sivapragasam M and Bustam MA. (2017). Extraction of $\beta$-carotene from organic phase using ammonium based ionic liquids aqueous solution. Journal of Molecular Liquids, 227, 1520.

[74] Kong L, Bhosale R and Ziegler GR. (2018). Encapsulation and stabilization of $\beta$-carotene by amylose inclusion complexes. Food Resource International, 105, 446-452.

[75] Story EN, Kopec RE, Schwartz SJ and Harris GK. (2010). An Update on the Health Effects of Tomato Lycopene. Annual Review of Food Science and Technology, 1, 189-210.

[76] Edwards AJ, Vinyard BT, Wiley ER, Brown ED, Collins JK, Perkins-Veazie P, Baker RA and Clevidence BA. (2003). Consumption of watermelon juice increases plasma concentrations of lycopene and beta-carotene in humans. Journal of Nutrition, 133, 1043-1050.

[77] Wink DA, Miranda KM, Espey MG, Pluta RM, Hewett SJ, Colton C, Vitek M, Feelisch M and Grisham MB. (2001). Mechanisms of the antioxidant effects of nitric oxide. Antioxidant and Redox Signal, 3, 203-213.

[78] Kim CH, Park MK, Kim SK and Cho YH. (2014). Antioxidant capacity and anti-inflammatory activity of lycopene in watermelon. International Journal of Food Science and Technology, 49, 2083-2091.

[79] Serra AT, Rocha J, Sepodes B, Matias AA, Feliciano RP, de Carvalho A, Bronze MR, Duarte CMM and Figueira ME. (2012). Evaluation of cardiovascular protective effect of different apple varieties-Correlation of response with composition. Food Chemistry, 135, 2378-2386.

[80] Figueroa A, Sanchez-Gonzalez M, Wong A and Arjmandi BH. (2012). Watermelon extract supplementation reduces ankle blood pressure and carotid augmentation index in obese adults with prehypertension or hypertension. America Journal of Hypertens, 25, 640-643.

[81] Barkura S, Bankapura A, Chidangila S and Mathura D. (2017). Effect of infrared light on live blood cells: role of $\beta$ carotene. Journal of Photochemistry and Photobiology, 171, 104-116.

[82] Rodríguez-Roque MJ, de Ancos B, Sánchez-Moreno C, Cano MP, Elez-Martínez P and Martín-Belloso 0. (2015). Impact of food matrix and processing on the in vitro bioaccessibility of vitamin c, phenolic. Journal of Functional Foods, 14, 33-43.

[83] Nzamwita M, Duodu KG and Minnaar A. (2017). Stability of $\beta$-carotene during baking of orange-fleshed sweet potato-wheat composite bread and estimated contribution to vitamin a requirements. Food Chemistry. 2, 228, 85-90.

[84] Maoto MM, Beswa D and Jideani AIO. (2019). Watermelon as a potential fruit snack. International Journal of Food Properties, 22(1), 355-370.

[85] Rao AV and Agarwal S. (1999). Role of lycopene as antioxidant carotenoid in the prevention of chronic diseases: A review. Nutritional Research, 19, 305-23.

[86] Gladvin G, Sudhaakr G, Swathi V and Santhisri KV. (2017). Mineral and vitamin compositions contents in watermelon peel (rind). International Journal of Current Microbiology and Applied Sciences, 5, 129-133.

[87] Abitogun AS, Ashogbon AO and Borokin FB. (2010). Nutritional and chemical compositions of ripe and unripe Vitex glandifolia. Journal of Research in National Development, 8(1), 1-5. 
[88] Olayinka BU and Etejere EO. (2018). Proximate and Chemical Compositions of Watermelon (Citrullus lanatus Thunb.) Matsum and Nakai cv Red and Cucumber (Cucumis sativus L. cv Pipino). International Food Research Journal, 25(3), 1060-1066.

[89] Doll S and Ricou B. (2013). Severe vitamin c deficiency in a critically ill adult: a case report. Journal of Clinical Nutrition, 67, 881-882.

[90] Pacier C and Martirosyan DM. (2015). Vitamin C: Optimal dosages, supplementation and use in disease prevention. Functional Foods in Health and Disease, 5, 89-107.

[91] Takeda K, Machida M and Kohara A. (2011). Effects of citrulline supplementation on fatigue and exercise performance in mice. Journal of Nutrition and Science Vitaminol. (Tokyo), 57, 246-250.

[92] Takahashi H, Mizuno H and Yanagisawa A. (2012). High-dose intravenous vitamin c improves quality of life in cancer patients. Personality and Medicine Universe, 1, 49-53.

[93] Soriano-Maldonado A, Hidalgo M, Arteaga P, de Pascual-Teresa S and Nova E. (2014). Effects of regular consumption of vitamin C-rich or polyphenol-rich apple juice on cardiometabolic markers in healthy adults: A randomized crossover trial. European Journal of Nutrition, 53, 1645-1657.

[94] Vaccaa RA, Valenti D, Caccamese S, Dagliac M, Braidy N and Nabavi SM. (2016). Plant polyphenols as natural drugs for the management of down-syndrome and related disorders. Neuroscience Bio behavioral Reviews, 71, 865-877.

[95] Choudhary BR, Jayaprakasha GK, Porat R and Patil BS. (2014). Low temperature conditioning reduces chilling injury while maintaining quality and certain bioactive compounds of star ruby grapefruit. Food Chemistry, 153, 243-249.

[96] Amamou F, Bouafia M, Chabane-Sari D, Meziane RK and Nani A. (2011). Citrullus colocynthis: a desert plant native in Algeria, effects of fixed oil on blood homeostasis in Wistar rat. Journal of Natural Products and Plant Resources, $1,1-7$.

[97] Chen JC, Chiu MH, Nie RL, Cordell GA and Qiu SX. (2005). Cucurbitacins and cucurbitane glycosides: structures and biological activities. Natural Product Report, 22, 386-399

[98] Kamboj A, Kaur R, Jain UK and Saluja AK. (2016) Quantitative estimation of cucurbitacin E in various extracts of Cucumis sativus L. by spectrometric method. Journal of Resreach in Ayurveda Pharmacy 7, 114-122.

[99] Davis AR, Weber CL and Fish WW. (2011). L-citrulline levels in watermelon cultigens tested in two environments. HortScience, 46, 1572-1575.

[100] Hong MY, Kaufman NH, Katy HS, Figueroa A and Kern M. (2015). Watermelon consumption improves inflammation and antioxidant capacity in rats fed an atherogenic dietary Nutritional Resources, 35, $251-258$.

[101] Allerton TD, Proctor DN, Stephens JM, Dugas TR, Spielmann G and Irving BA. (2018). L-citrulline supplementation: Impact on cardiometabolic health. Nutrients, 10(291), 1-24

[102] Bailey SJ, Blackwell JR, Williams E, Vanhatalo A, Wylie LJ, Winyard PG and Jones AM. (2016). Two weeks of watermelon juice supplementation improves nitric oxide bioavailability but not endurance exercise performance in humans. Nitric Oxide Biology and Chemistry, 59, 10-20.

[103] Tong BC and Barbul A. (2004). Cellular and physiological effects of arginine. Mini Reviews in Medicinal Chemistry, 4, 823-832.

[104] Flynn NE, Meininger CJ, Haynes TE and Wu G. (2002). The metabolic basis of arginine nutrition and pharmacotherapy. Biomedicine and Pharmacotherapy, 56, 427-438.

[105] Perkins-Veazie and Collins JK. (2002). Watermelon: Lycopene content changes with ripeness stage, germplasm, and storage. Cucurbitacea, 427-430.

[106] Odewunmi NA, Umorena SA, Gasema ZM, Ganiyub SA and Muhammad Q. (2015). L-Citrulline: an active corrosion inhibitor component of watermelon rind extract for mild steel in HCL medium. Journal of Taiwan Institute. Chemical Engineering, 51, 177-185.

[107] Figueroa A, Wong A, Jaime SJ and Gonzales JU. (2017). Influence of L-citrulline and watermelon supplementation on vascular function and exercise performance. Current Openion, 20(1), 92-98.

[108] Abourashed EA. (2013). Bioavailability of plant-derived antioxidants. Antioxidants, 2, 309-325. 
[109] Feng M, Ghafoor K, Seo B, Yang K and Park J. (2013). Effects of ultraviolet-C treatment in Teflon-coil on microbial populations and physico-chemical characteristics of watermelon juice. Innovative Food Science Emerging Technology, 19, 133-139.

[110] Barba FJ, Terefe NS, Buckow R, Knorr D and Orlien V. (2015). New opportunities and perspectives of highpressure treatment to improve health and safety attributes of foods. A Review. Food Research International, 77, 725-742.

[111] Anaya-Esparza LM, Vel-azquez-Estrada RM, Roig AX, García-Galindo HS, Sayago-Ayerdi SG and MontalvoGonzalez E. (2017). Thermo sonication: an alternative processing for fruit and vegetable juices. Trends of Food Science Technology, 61, 26-37

[112] Mohd-Alia M, Hashima N, Bejoa SK and Shamsudin R. (2017). Rapid and nondestructive techniques for internal and external quality evaluation of watermelons: A Reviewed Science of Horticulture, 225, 689-699.

\section{How to cite this article}

Aderiye BI, David OM, Fagbohun ED, Faleye J and Olajide OM. (2020). Immunomodulatory and phytomedicinal properties of watermelon juice and pulp (Citrullus lanatus Linn): A review. GSC Biological and Pharmaceutical Sciences, 11(2), 153-165. 